\title{
Confocal microscopy of idarubicin localisation
}

\section{Sir}

We have read with interest and some surprise the paper recently published in the British Journal of Cancer: Confocal microscopy of idarubicin localisation in sensitive and multidrug resistant bladder cancer cell lines (Br. J. Cancer 1996; 74: 906-909) by Duffy, Hayes, Cooper and Smart, from Southampton.

A factor that has not been taken into account by the authors and which would significantly modify their conclusions is the fact that there is a $98 \%$ quenching of fluorescence when an anthracycline is intercalated between DNA base pairs. This means that the nuclear signal of anthracycline fluorescence has to be multiplied by 50 to be compared with the cytoplasmic nuclear signal. The confocal microscopic study performed by the authors is in no way quantitative and the rough comparison of the visual signals (cytoplasm vs nuclear) cannot bring any conclusions concerning the subcellular distribution of the drug. The differences pointed out by the authors between doxorubicin and idarubicin are not sustained by any quantitative data and cannot be interpreted. We would advise the authors to use confocal microspectrofluorometry, a technique that allows absolute measurements of anthracycline nuclear concentration (Gigli et al, 1988, 1989). Such a technique applied to idarubicin has already been performed in Reims and has led to the conclusions that the behaviour of idarubicin is not qualitatively different from that of doxorubicin or other anthracyclines.

\author{
Professeur M Manfait \\ Faculté de Pharmacie, \\ 51, rue Cognacq-Jay, \\ 51096 Reims Cedex \\ Professeur J Robert \\ Institut Bergonié, \\ 180, rue de Saint Genès, \\ 33076 Bordeaux
}

\section{REFERENCES}

Gigli M, Doglia SM, Millot JM, Valentini L and Manfait M (1988) Quantitative study of doxorubicin in living cell nuclei by microspectrofluorometry. Biochim Biophys Acta 950: 13-20

Gigli M, Rasoanaivo T, Millot JM, Jeannesson P, Rizzo V, Jardiller JC, Arcamone F and Manfait M (1989) Correlation between growth inhibition and intranuclear doxorubicin and $4^{\prime}$-deoxy-4'-iododoxorubicin quantitated in living K 562 cells by microspectrofluorometry. Cancer Res 49: 560-564

\section{Confocal microscopy of idarubicin localisation - reply}

\section{Sir}

Professors Manfait and Robert highlight the difficulty in interpreting nuclear/cytoplasmic fluorescence in the presence of quenching. This is a dilemma addressed in our original article and our findings regarding this phenomenon are presented in Figure 5. The data show that differences in fluorescence quenching between idarubicin and conventional anthracyclines (in free solution with DNA) appear insufficient to account for the consistent differences in nuclear/cytoplasmic fluorescence observed in our studies. We have also more recently repeated the studies using nuclei isolated from our cell lines by zaponin in the presence of protease and phosphatase inhibitors. Idarubicin fluoresces in stripped nuclei as effectively as epirubicin. We will publish these results as soon as possible in view of their relevance to this controversy. Overall, we feel that we have demonstrated a distinction between intracellular idarubicin fluorescence and that of less lipophilic anthracyclines that is not explained by fluorescence quenching phenomena.

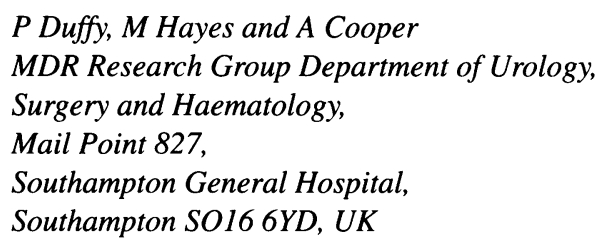

\section{Colorectal carcinoma: some reflections on bile flow through the terminal ileum}

\section{Sir}

I have just read with great interest the paper by Boutron et al (1996). They suggest that the type of dairy product might be the important factor with regard to prevention of colorectal tumours.
It is widely believed that bile salts may have some role in colorectal carcinoma (CRC) (Nagengast, 1988; Garewal et al, 1996). The enzyme diamine oxidase (DAO), which is a major catabolic enzyme for histamine, is found in highest concentration 


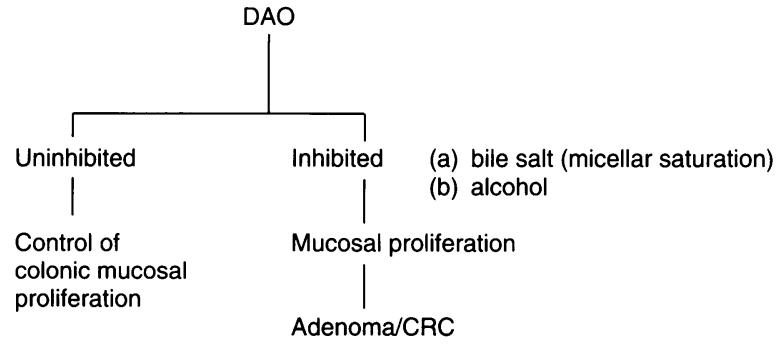

Figure 1 Summary of possible DAO effect in the terminal ileum

in the ileal mucosa (Lessof et al, 1990). DAO is thought to be involved in the possible inhibition of colonic mucosal proliferation (Kusche et al, 1988). It has been shown that DAO activity can be reduced in vitro by several factors including detergent (Sattler et al, 1987), and bile salt (Stoneham et al, 1993). Alcohol has also been thought to inhibit DAO in vivo (Wantke et al, 1993). There appears to be a limit to cholesterol solubility in the bile salt micelle (Chijiwa and Nagai, 1987a,b) that might lead to variable amounts of free bile salt in the lumen of the terminal ileum with different dietary fat intakes. These statements are summarized in Figure 1.

Could these mechanisms in vivo go some way to explain the geographical variations in colorectal cancer incidence that have been correlated with different regional dietary patterns (Armstrong and Doll, 1975; Bingham, 1990), and also the possible link with cholecystectomy? (Ekbom et al, 1993; Giovanni et al, 1993). Could the possible inhibition of DAO by alcohol help in understanding the role of alcohol ingestion in colorectal carcinoma (Hirayama, 1989)? If the importance of DAO inhibition is established in vivo, could the susceptibility of certain families to colorectal cancer (Petersen, 1995; Winawer et al, 1996) be partly related to genetic variants of DAO?

\author{
Michael Stoneham \\ UHCE \\ Institute of Health Sciences \\ Old Road \\ Oxford OX3 $7 L F$
}

\section{REFERENCES}

Armstrong B and Doll R (1975) Environmental factors and cancer incidence and mortality in different countries, with special reference to dietary practices. Int $J$ Cancer 15: 617-631

Bingham SA (1990) Diet and large bowel cancer. J Roy Soc Med 83: 420-421

Boutron MC, Faivre J, Marteau P, Couillart C, Senesse P and Quipourt V (1996) Calcium, phosphorus, vitamin $\mathrm{D}$, dairy products and colorectal carcinogenesis: a French case-control study. Br J of Cancer 74: 145-151

Chijiwa K and Nagai M (1987a) Interaction of bile salt monomer and cholesterol in the aqueous phase. Biochim Biophys Acta 1001: 111-114

Chijiwa K and Nagai M (1987b) Bile salt micelle can sustain more cholesterol in the intermicellar aqueous phase than the maximal aqueous solubility. Arch Biochem Biophys 20: 422-477

Ekbom A, Yuen J, Adami H, McLaughlin JK, Chow W, Persson I and Fraumeni JF (1993) Cholecystectomy and colorectal cancer. Gastroenterology 105: $142-147$

Garewal H, Bernstein H, Bernstein C, Sampliner R and Payne C (1996) Reduced bile acid-induced apoptosis in 'normal' colorectal mucosa: a potential biological marker for cancer risk. Cancer Res 56: 1480-1483

Giovanni E, Colditz GA and Stampfer MJ (1993) A meta-analysis of cholecystectomy and risk of colorectal cancer. Gastroenterology 105 : 130-141

Hirayama T (1989) Association between alcohol consumption and cancer of the sigmoid colon: observations from a Japanese cohort study. Lancet 2 : 725-727

Kusche J, Mennigen R, Leisten L and Krahamp B (1988) Large bowel tumor promotion by diamine oxidase inhibition: animal model and clinical aspects. Agents Actions 23: 351-353

Lessof M, Grant V, Hinuma K, Murphy GM and Dowling RH (1990) Recurrent urticaria and reduced diamine oxidase activity. Clin Exp Allergy 20: 373-376

Nagengast FM (1988) Bile acids and colonic carcinogenesis. Scand J Gastroenterol 23 (suppl. 54): 76-81

Petersen GM (1995) Genetic epidemiology of colorectal cancer. Eur J Cancer 31A: 1047-1050

Sattler J, Hesterberg R, Chmidt U, Crombach M and Lorenz W (1987) Inhibition of intestinal diamine oxidase activity by detergents: a problem for drug formulations with water insoluble agents applied by the intravenous route? Agents Actions 20: 270-273

Stoneham MD, Young E and Wilkinson JD (1993) Dietary manipulation of fat in chronic urticaria. J Derm Treat 4: 183-185

Wantke F, Demmer CM, Gotz M and Jarisch R (1993) Inhibition of diamine oxidase is a risk in specific immunotherapy. Allergy 48: 552

Winawer SJ, Zauber AG, Gerdes H, O’Brien MJ, Gottlieb LS, Sternberg SS, Bond JH, Waye JD, Schapiro M, Panish JF, Kurtz RC, Shike M, Ackroyd FW, Stewart ET, Skolnick M, Bishop DT and the National Polyp Study Workgroup (1996) Risk of colorectal cancer in the families of patients with adenomatous polyps. N Engl J Med 334: 82-87 